\title{
Modelling wind-driven rain on buildings in urbanized area using 3-D GIS and LiDAR datasets
}

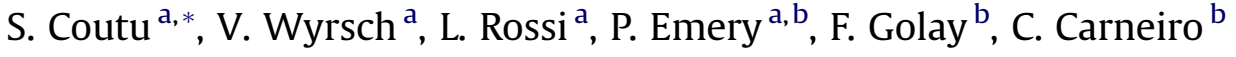 \\ ${ }^{a}$ ECOL, Faculté de l'environnement Naturel, Architectural et Construit (ENAC), Station 2, École Polytechnique Fédérale de Lausanne (EPFL), GR A1 445 (Bâtiment GR), \\ 1015 Lausanne, Switzerland \\ ${ }^{\mathrm{b}}$ LASIG, Faculté de l'environnement Naturel, Architectural et Construit (ENAC), Station 2, École Polytechnique Fédérale de Lausanne (EPFL), 1015 Lausanne, Switzerland
}

\section{A R T I C L E I N F O}

\section{Article history:}

Received 26 June 2012

Received in revised form 27 September 2012

Accepted 30 September 2012

\section{Keywords:}

Urban environment

Wind-driven rain

Building envelopes

GIS

\begin{abstract}
A B S T R A C T
This study investigated the distribution of the fraction of rainfall intercepted by the facades of buildings located in an urbanized area. We used the frequently used semi-empirical standard ISO-15927-3 to simulate Wind-Driven Rain on facades. The implementation of the Norm on a neighbourhood scale required a list of parameters, including building geometry and terrain characteristics. For the first time, we proposed the use of combined 3-D GIS and LiDAR data to retrieve all the information necessary to apply the Norm on a large set of buildings. The proposed methodology was tested on a dense urban area of 242 buildings with a wide range of original features. The distributions of simulated catch ratios per facade were exponentially distributed between 0 and $9 \%$. Results obtained were smaller than those usually identified in the literature. This was in large part explained by two points: (i) the buildings considered are located in a dense urban area where surrounding buildings create an obstruction factor that limits WDR on facades and, (ii) not only are windward facades considered, but also facades located in the dominant wind direction which received almost no rain. Facade orientation is a clear factor that influenced the amount of rainfall in contact with it. Modern GIS techniques are sufficiently advanced to provide the necessary information to assess WDR. However, the accuracy of our conclusion was limited by the inherent simplicity of the Norm, which has potential for improvement in terms of the definition of the obstruction factor and the range of building geometry which it takes into consideration.
\end{abstract}

(c) 2012 Elsevier Ltd. All rights reserved.

\section{Introduction}

The volume of water contacting building facades because of the Wind-Driven Rain (WDR) effect is one of the current issues in building sciences. Wind-Driven Rain (WDR) refers to the oblique component of the rain vector when wind and rain occur simultaneously [1]. Wind fields determine the direction of rainfall. Thus, wind field and rain intensity are the two factors that determine WDR. WDR is of general interest in hydrology and has been the source of consistent efforts in research [2-5]. In fact, WDR has been evaluated as the most important source of humidity having effects on hygrothermal performance and durability of building facades [6-8]. After contact with facades, rain water infiltrates into the building and can alter construction materials via frost damage [9$11]$, or other moisture-related causes $[12,13]$. In recent studies, the wash-off process of biocides used in paints and renders for prevention of algea and fungi due to WDR was found to be a considerable source of biocides in urban waters [14-16].

\footnotetext{
* Corresponding author. Tel.: +41 (0) 216938024

E-mail address: sylvain.coutu@epfl.ch (S. Coutu).
}

A better knowledge of WDR - facade interaction would help to quantify these persistent issues and reduce costs related to building that have been observed to be in constant rise [17,18]. It could help also in prioritizing insulation of the most exposed facades, contributing to reduction of energy demand for heating. Finally, there is a tendency in Europe to densify the built environment [19]. The impact of this densification process on the building envelope has not been considered until now. Our knowledge on the interception of WDR by buildings gets regular inputs from the scientific literature $[6,20,21]$. However, too few studies have been carried out within the urban environment, where complex wind fields/buildings interactions must be considered [18,22,23].

Three different kinds of methodologies have so far been tested to estimate WDR and the fraction of water intercepted by building during rain events, commonly called catch ratio: (i) experimental methods, (ii) empirical methods and, (iii) numerical methods. Each of these methodologies have their own characteristics, drawbacks and advantages. The reader can refer to Blocken Blocken and Carmeliet [18] for an excellent review.

An ISO Norm 15927-3 [24] has been proposed with the aim of defining an international standard for the procedure of estimating 
WDR. The Norm proposes two methods to compute WDR but only the first one, more advanced as requiring hourly rainfall and wind speed, will be considered in this study. The estimation derived from this norm is based on local meteorological data and building characteristics. It consists of the estimation of WDR on a freestanding facade in flat open country which is then adjusted to take factors such as the roughness of the terrain, topography, nearby obstacles and building geometry into consideration. It is currently one of the most advanced and most frequently used methodologies to estimate WDR volumes on facades $[25,26]$. The legitimacy and accuracy of this Norm has been investigated in a series of publications [25-28]. However, applications of this Norm have so far been limited to case studies of isolated buildings. In this paper, we propose using the specified Norm to extrapolate distributions of the WDR catch ratio for all facades in a predetermined urban neighbourhood.

To apply this Norm to dense urban regions, numerous information on buildings themselves (facade orientation and height, roof slope, number of floors, etc) and on the local environment (terrain topography, distance to the nearest obstacle, etc) are required. Nowadays, this kind of information is commonly collected and managed using 3-D Geographical Information Systems (GIS). During the last years 3-D GIS systems have demonstrated their wide range of utility in activities related to the sustainable development of cities [29]. One of the available techniques allowing projects based on 3-D GIS to be implemented and developed is the well-known remote sensing technique called LiDAR (Light Detection And Ranging) technology. It integrates sensors in order to obtain very accurate 3-D coordinates of points located on the surface of the earth, such as ground points, buildings and trees. In order to establish the position of the sensor each time a point is measured, the Global Positioning System (GPS) is used. For more details, please consult Baltsavias [30]. Data derived from LiDAR technology can be used, for instance, on the extraction of valuable and useful urban indicators such as the assessment of the solar potential of roofs [31], the estimation of urban tree crown volume [32] or the analysis of the urban form [33].

In this manuscript, we combine the existing ISO Norm 15927-3 with 3-D GIS and LiDAR technology to estimate distributions of WDR catch ratios on a neighboorhood scale. In addition, we discuss (i) the influence of building and environmental characteristics on output results, (ii) the conditions this norm can actually be applied to real case studies and, (iii) the level detail needed to apply this norm. After a brief description of the ISO norm 15927-3, this paper applies the proposed methodology to the community of Thônex, South-West of the city of Geneva, Switzerland. Community constituted of 242 buildings, densely arborized in a $1 \mathrm{~km}^{2}$ area.

\section{Wall spell index and catch ratio after ISO norm 15927-3}

In our approach we use a model for generating WDR based on the ISO Norm 15927-3. The goal is to compute a "catch-ratio" ( $\left.C_{W S}\right)$, defined as the fraction of rain water intercepted by vertical facades divided by the horizontal component of precipitation $\left(P_{h}\right)$ [34]. This ratio can be calculated with:

$C_{W S}=\frac{I_{W S}}{P_{h}}$.

The wall spell index $I_{W S}\left[1 / \mathrm{m}^{2}\right]$ is defined as the "quantity of winddriven rain per square meter at a point on a given wall, based on the airfield spell index and corrections for roughness, topography, obstruction and wall factors " [24]. A spell is defined to be "[...] a period of driving rain [...] in which the input of water due to the driving rain exceeds the loss due to evaporation. [...] A gap between two spells is [...] defined by a period of at least $96 \mathrm{~h}$ of no water getting to the façade" [24]. The wall spell index is calculated as:

$I_{W S}=I_{S} \times C_{R} \times C_{T} \times O \times W$.

It is composed of the airfield spell index $I_{S}\left[1 / \mathrm{m}^{2}\right]$ multiplied with coefficients representing the influence of the surroundings on the facade concerned. $C_{R}$ is the roughness coefficient, which considers terrain roughness in wind direction and the variability of wind velocity depending on the height of facades. $C_{T}$ is the topography coefficient. It increases the airfield spell index if the area investigated is placed on a cliff or on the upper part of a hill. $O$ corresponds to the obstruction factor. Presence of obstacles surroundings the facade reduces the amount of rain getting to the building. These effects are included in this coefficient. $W$ stands for the wall factor. It aims to account for the variability of building geometry and its impact on rain reaching the facades. Typical range of values for all variables introduced can be found in the considered Norm. More information on how to calculate each variable can be found in the Norm. Yet, we describe in the following parts of this manuscript how to extract the necessary parameters (see list in Table 1) in order to compute them. The airfield spell index $I_{S}$ is calculated from the temporal distribution of its proxy $I_{S}^{\prime}$ as follows:

$I_{S}^{\prime}=\frac{2}{9} \sum v \times r^{8 / 9} \times \cos (D-\theta)$,

$v$ is the hourly mean wind speed in [m/s], $r$ is the total hourly rainfall in [mm], $D$ corresponds to the hourly mean wind direction with respect to North [-], in and $\theta$ is the facade orientation relative to north. If $\cos (D-\theta)>0$, the wind drives the rain toward the facade otherwise the rain will have no significant or no effect on the wall and $I_{S}^{\prime}$ is set to zero. To calculate the airfield spell index with $I_{S}^{\prime}$ the 67 percentile must be found:

$I_{S}=67 \%$ percentile of $I_{S}^{\prime}$.

The 67 percentile is found from the values of $I_{S}^{\prime}$ for all the spells within the period of available meteorological data (wind velocity, wind direction and the hourly sum of precipitation). The 67 percentile corresponds accordingly to the Norm to the maximum value of $I_{S}^{\prime}$ likely to occur once every three years. The airfield spell index $I_{S}$ corresponds to the amount of water falling on a freestanding wall in flat open country during the worst spell likely to occur within three years. In this sense, the reference unit of the norm, the wall spell index $I_{W S}$, is the amount of water falling on a facade during the most intense spell likely to occur within three years when obstacles are considered (see Table 1 for a list).

Similar to $C_{W S}$ (Eq. (1)), we can define the catch ratio $C_{S}$ for a wall in a free-standing area, i.e. the fraction of water getting to the vertical surface without consideration of damping coefficients (Eq. (2)). $C_{S}$ is expressed with:

Table 1

Necessary data obtained from 2-D GIS, 3-D GIS, LiDAR or DTM (Digital Terrain Model) to compute the ISO methodology.

\begin{tabular}{llll}
\hline Parameter & Unit & $\begin{array}{l}\text { Building (b)/ } \\
\text { Facade (f) }\end{array}$ & Source \\
\hline $\begin{array}{l}\text { Facade orientation } \\
\text { relative to north }\end{array}$ & $\varnothing$ & $\mathrm{f}$ & 2-D GIS \\
$\begin{array}{l}\text { Facade height } \\
\text { Eaves }\end{array}$ & Meter & f & LiDAR \\
Roof slope & $\varnothing$ & $\mathrm{f}$ & 3-D GIS \\
$\begin{array}{l}\text { Distance to the } \\
\text { nearest obstacle }\end{array}$ & $\varnothing$ & b & LiDAR \\
Terrain topography & $\varnothing$-ter & $\mathrm{f}$ & 2-D GIS/LiDAR \\
Number of floors & $\varnothing$ & $\mathrm{b}$ & DTM \\
\hline
\end{tabular}




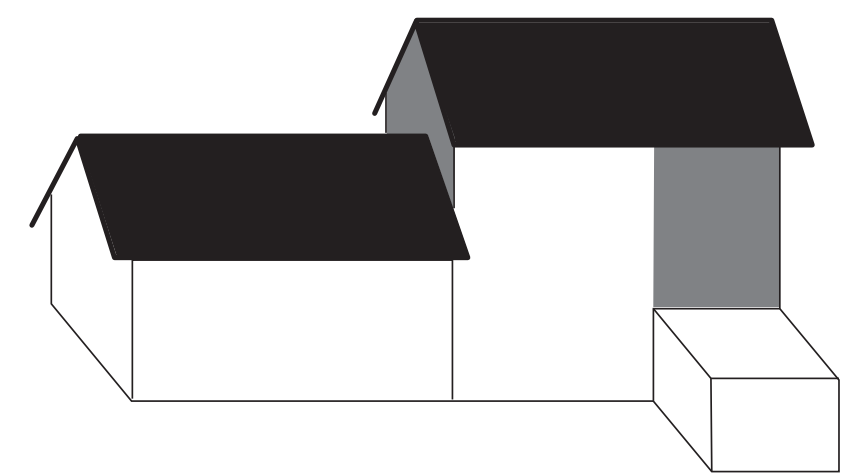

Fig. 1. Typical cases of attached buildings where inner facades (marked in grey) are present.

$C_{S}=\frac{I_{S}}{P_{h}}$

$C_{S}$ and $C_{W S}$ are the two parameters that will be discussed in this study.

A methodology to obtain numerical values for the different parameters in Eqs. (1)-(4) from meteorological data and a 3-D GIS database is presented in following paragraphs.

\section{3-D GIS data processing}

All data which must be obtained for application of the ISO Norm are presented in Table 1 . Potential sources for retrieving this information are shown in the same table. The 3-D GIS database formed is based on various information: (1) 3-D vector data of building roofs, (2) 2-D vector data information of building footprints, and (3) LiDAR data, mostly used for the classification of vegetation.

The 3D-data needed to calculate the wall spell index of the facades can be processed with the aid of the GIS-program Manifold. ${ }^{1}$ Some of the expressions in this section may refer to this program.

A first simplification that is made prior to the model parameters estimate is the elimination of inner facades. Some buildings consist of several houses attached to each other. These buildings may have different heights, which lead to the existence of inner facades (see Fig. 1). For calculations, however, these inner facades are not considered since they are not mentioned in the ISO Norm. Thus, the separate houses are condensed into one building, as shown in the following example (Fig. 2). For the facade height the average value is taken.

\subsection{Wall orientation relative to north}

The orientation of the walls towards North is given in degrees and in clockwise direction for the exterior side of the wall (Fig. 3).

\subsection{Height of facades, buildings and number of floors}

Facade heights differ from building heights, this last parameter being straightforwardly available in the cadastral database. To stay as close as possible to the norm, facade height for each building is found by overlapping two GIS layers: one contains building elevation in each of its pixels, and the other shows facades localization. The intersection of these two layers provides the height of each facade.

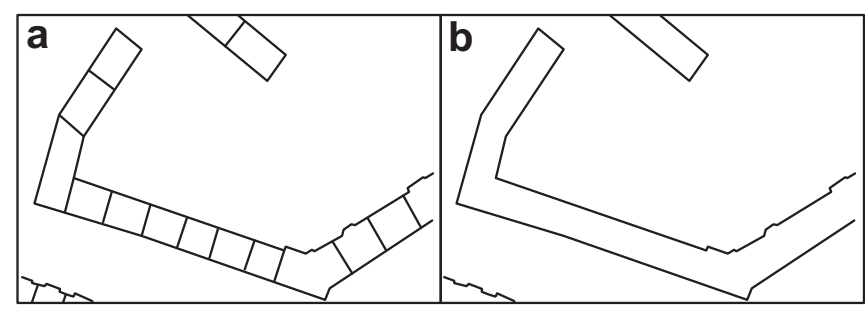

Fig. 2. Overhead view showing the same building (a with and (b without consideration of inner facades. Height of the proxy building in b) is the average height of buildings it is constituted of.

\subsection{Eaves presence determination}

Facades with eaves are determined by subtracting a GIS layer containing the projected view of the building on the ground to the layer containing ground print of the building (see Fig. 4). According to the ISO Norm, eaves are considered if the space between the facade and the end of the roof is larger than $35 \mathrm{~cm}$.

\subsection{Roof slope}

Prior to evaluating the roof slope of a building, structures present on the roof (like chimneys) have first been removed (see Fig. 5) as they constitute a strong irregularity of the roof slope, distorting the average value of the real roof slope. Afterwards, the average slope of the 3-D surface obtained from LiDAR is computed for each building [35]. The ISO Norm defines sloping roofs as at least $20^{\circ}$ pitched roofs. Finally, a query allows a distinction between flat and sloping roofs to be made by separating roofs with a mean slope of more than $20^{\circ}$ from the ones with a mean slope of $20^{\circ}$ or less.

This procedure works correctly for common roofs such as, for example, the house on the top left corner of Fig. 5. For more complex roofs (house in bottom left corner of Fig. 5) the average value in certain cases may differ from the reality. The ISO Norm does not provide a rule to handle complex roofs. What is needed in the end is the information whether the roof over a given facade is flat or pitched $\left(>20^{\circ}\right)$.

\subsection{Horizontal distance to the nearest obstacle}

The horizontal distance to the nearest obstacle (vegetation or another building) within the line of sight $\left(25^{\circ}\right.$ on either side of the normal to the wall, see Fig. 6) with at least the same height as the facade considered can be found by applying two queries specifically developed for this study. One of the queries looks for the nearest vegetative obstacle (mainly trees) with the same height or higher while the second searches for buildings with equal or higher height. In this way, the smallest distance to both the plant and the building

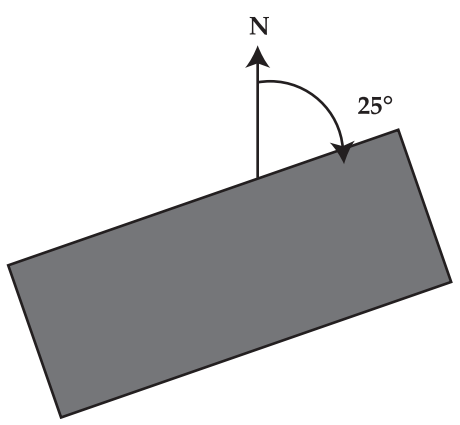

Fig. 3. Definition of facade orientation towards North.

\footnotetext{
${ }^{1}$ http://www.manifold.net/, site last accessed in March 2012.
} 

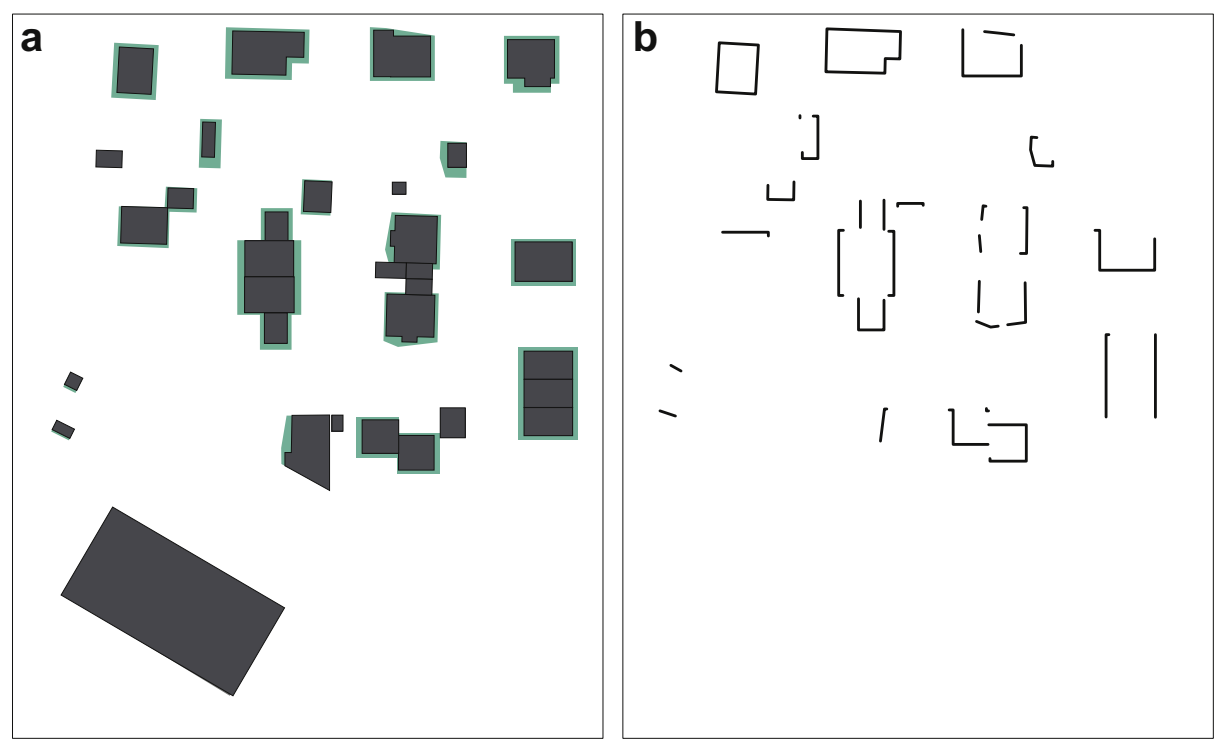

Fig. 4. Identification of facades with eaves. a) superposition of roof and soil print, b) identified facades with eaves.

fulfilling the criteria mentioned is found for every facade. The smaller distance of the two is taken in order to find the corresponding obstruction factor.

The distance to the nearest obstacle is necessary to evaluate the obstruction factor as stipulated in the ISO Norm (See Table 2). Curiously, no value of obstruction factor is given if the obstacle is located at less than $4 \mathrm{~m}$ from the facade. For such cases, the obstruction factor is assumed here to be zero if the obstacle is closer than $1 \mathrm{~m}$, and 0.1 if its distance to the facade is between 1 and $4 \mathrm{~m}$. If the obstruction factor is zero, IWS becomes zero as well. This would make sense for obstacles which are placed very closely to the facade considered and thus hinder any rain falling on the facade.

\subsection{Terrain topography}

Information on terrain topography is necessary to obtain two geographical parameters. The first one is the terrain category, which provides information on the roughness of the terrain at a given height [24]. Roughness of the terrain influences wind velocity and thus impacts $I_{W}$ by a factor $C_{R}$. Terrain category is found from the distribution of building height in the area considered, and from the proportion of surface that is covered with buildings [24]. The second parameter is the topography coefficient $C_{T}$ which accounts for slope effects on wind intensity. Indeed, the ISO Norm considers increases in mean wind speed over isolated hills and escarpments. The topography coefficient is obtained from Digital Terrain Model (DTM). Terrain category and $C_{T}$ are two factors that are site specific i.e., the value considered is the same for all buildings included in the area considered.

\subsection{Wall factor}

The amount of rain getting to the facades is partly determined by building geometry. This is accounted for in the Norm with the wall factor $(W)$. The wall factor is characteristic of a facade. Fig. 7 presents the different wall factors depending on the roof angle, overhangs of the roof and the number of floors.

The ISO Norm gives for each type of wall the distribution of the wall factor over the whole facade. However, in this project it is

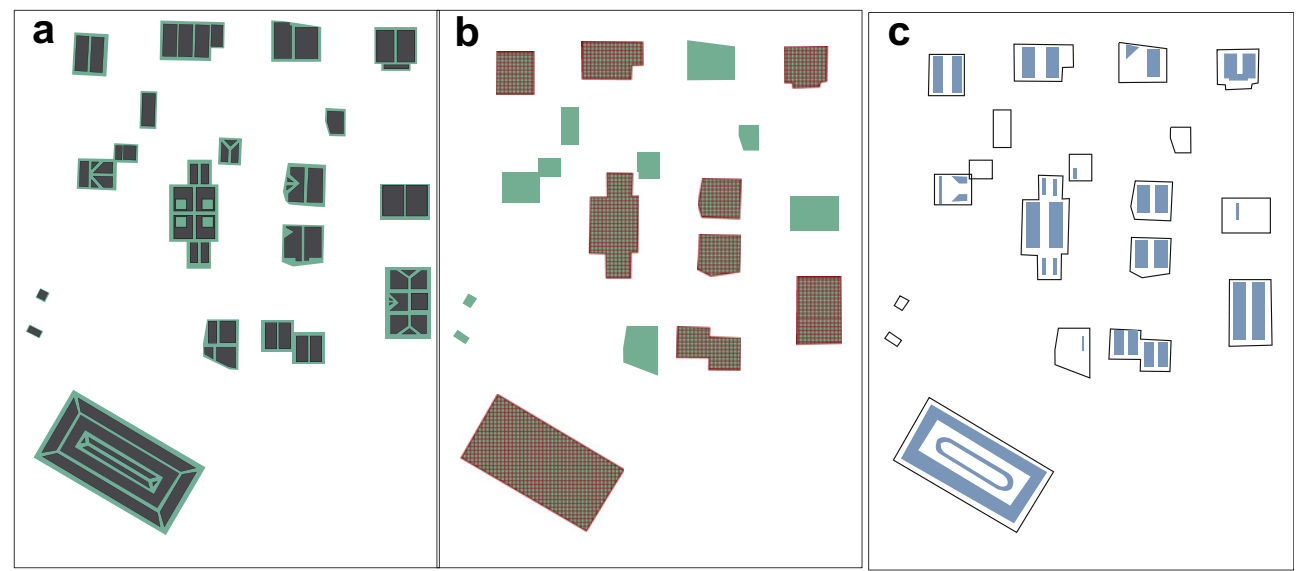

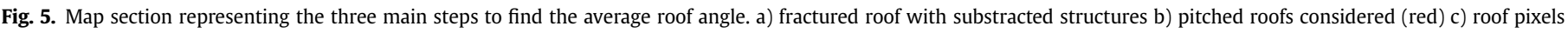
with slope $>20^{\circ}$ (in blue). (For interpretation of the references to colour in this figure legend, the reader is referred to the web version of this article.) 


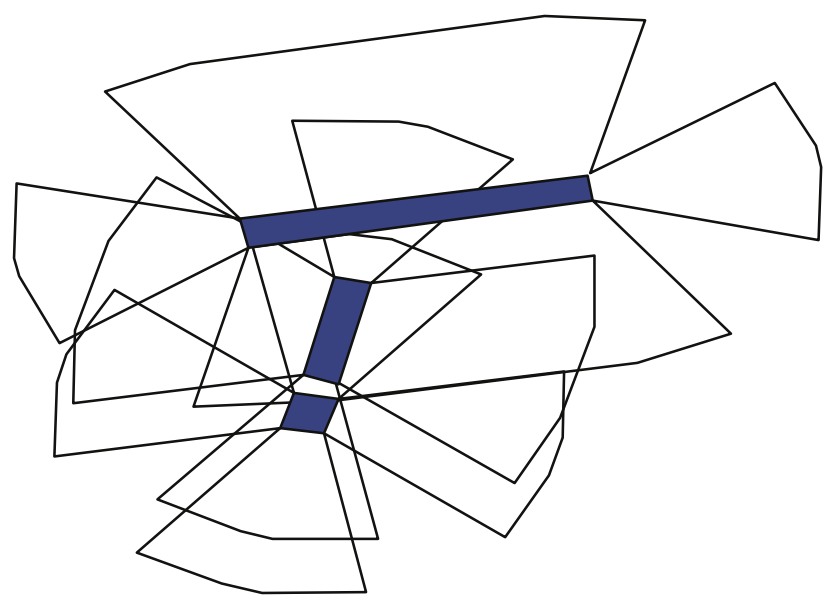

Fig. 6. Illustration of one procedure part of the query whereby the obstacle searching area of the facades of three buildings are defined.

assumed to be sufficient just to take the average value of the wall factor on the facade.

Besides, the ISO Norm indicates the wall factor of only a few types of buildings. There is no information given for buildings with less than two floors. Also, information about multi-storey buildings ( $>3$ floors) with a pitched roof is missing. For these cases assumptions are made based on the information of the building types documented in the ISO Norm (see Fig. 7). In the case of buildings with four or more floors, it is assumed that the presence of eaves does not influence the wall factor of the facade. This assumption is supported by existing studies that have shown that for high-rise buildings, the wind-blocking effect is the main factor that governs the WDR distribution pattern on a facade, and not the occurrence of eaves [36,37]. The presence of eaves has more influence on low-rise buildings. So by analogy with coefficients given for two-storey building gables or with eaves in the Norm (see Fig. 7), the assumption is made that for one-storey buildings the average wall factor is reduced by 0.1 in presence of eaves.

\section{Field case illustration}

The investigated area tested to apply our methodology is located in the community of Thônex in the southeast of Geneva, Switzerland. This area contains 242 buildings of different types (households, administrative and industrial) and sizes (Fig. 8). The number of facades is 1497 . The terrain considered is a suburban flat (Category III, $C_{T}=1$ ) area. Its surface area is $1 \mathrm{~km}^{2}$. All data listed in Table 1 necessary to compute WDR catch ratio in facades were supplied by the Direction Cantonale de la Mensuration Officielle ${ }^{2}$ (DCMO), Geneva.

The following meteorological data are necessary to implement the ISO Norm: (i) rain intensity, (ii) wind speed and, (iii) wind direction. According to the Norm, data should be from an observation period of at least ten (better twenty or thirty) years with an hour time resolution. For our case study, the weather station providing the meteorological data is at Genève-Cointrin. This station belongs to the Swiss meteorological network. The consistency of data has been checked with other nearby stations. The observations started on 1 January 1981 at 0.00 a.m. and ended on 19 July 2011 at 11.00 a.m., which corresponds to an observation period of more than 30 years. Data are provided at an hour time resolution.

\footnotetext{
${ }^{2}$ http://etat.geneve.ch/dt/dcmo/accueil.html, site last accessed in March 2012.
}

\section{Results and discussion}

The distribution of the wall catch ratio ( $C_{W S}$, Eq. (1)) and the airfield catch ratio $\left(C_{S}\right.$, Eq. (5)) calculated for all the facades of the area considered is presented Fig. 9.

The wall catch ratios calculated have a mean value of $0.56 \%$, with a distribution of values ranging from 0 to $9 \%$. For the airfield catch ratio, which is the fraction of water getting to a vertical surface without consideration of damping coefficients, values range between 0.01 and 1.2, with an associated mean value 0.197 of (i.e., 19.7\%). Note that the airfield catch ratio can exceptionally take values higher than one when intense wind condition occurs in open an area.

The distribution of the wall catch ratios in this study are small compared with other existing studies aiming to investigate this parameter. Usually, typical average wall catch ratios range between $10 \%$ and $25 \%$ [27,38-40], which means high discrepancies with values simulated in this project. A recent study by Burkhardt et al. [41] conducted on a West oriented facade under natural condition estimated a catch ratio of $6.3 \%$ after one year of exposure. But while comparing the different results, attention must be paid to measurements, simulations and boundary conditions. In all papers identified, the typical catch ratio values presented are given in prevailing wind direction. Also, selected buildings for research study are idealized or located in an isolated area [25,27,42]. This again will obviously increase the amount of rain getting to a facade as it is not protected by any obstacles. In all cases the absence of obstacles as well as the orthogonal wind direction to the facade can be considered as special cases in the ISO Norm. For this reason, the values found in the literature are located between the range of values of the airfield catch ratio found in this study. Considering the buildings inside a dense urban environment seems to reduce strongly the impact of WDR on its facades.

The impact of building height, the presence of eaves, number of floors, flat roofs, distance to the nearest obstacle and facade orientation on the wall catch ratio is investigated in Fig. 10. As expected, we see that facade orientation is the main factor impacting WDR on facades because windward facade protects partly or fully other facades from rain impact by distorting wind fields around the building [18,42]. Similarly, the decreasing distance from the nearest obstacle higher to the facade reduces the amount of WDR rain on the facade. This is logical considering the definition of the nearest obstacle (section 3.5). However, this definition can be contested by the studies of Blocken et al. [28] and Blocken et al. [43], who show that the influence of smaller buildings can actually increase WDR on higher buildings, which is not accounted for in the Norm used as the reference model for this study. On the other hand, the presence of eaves and the height of the building do not reveal a pattern of WDR catch ratios. This again is supported by other external studies. If overhang roof has been

\section{Table 2}

Obstruction factor $(\mathrm{O})$ values. Table adapted from the Norm. Shaded lines complete the Norm for its application to real case study.

\begin{tabular}{ll}
\hline Distance to obstacle $(\mathrm{m})$ & Obstruction factor $(\mathrm{O})$ \\
\hline From 0 to 1 & 0 \\
From 1 to 4 & 0.1 \\
From 4 to 8 & 0.2 \\
From 8 to 15 & 0.3 \\
From 15 to 25 & 0.4 \\
From 25 to 40 & 0.5 \\
From 40 to 60 & 0.6 \\
From 6 to 80 & 0.7 \\
From 80 to 100 & 0.8 \\
From 100 to 120 & 0.9 \\
Over 120 & 1 \\
\hline
\end{tabular}




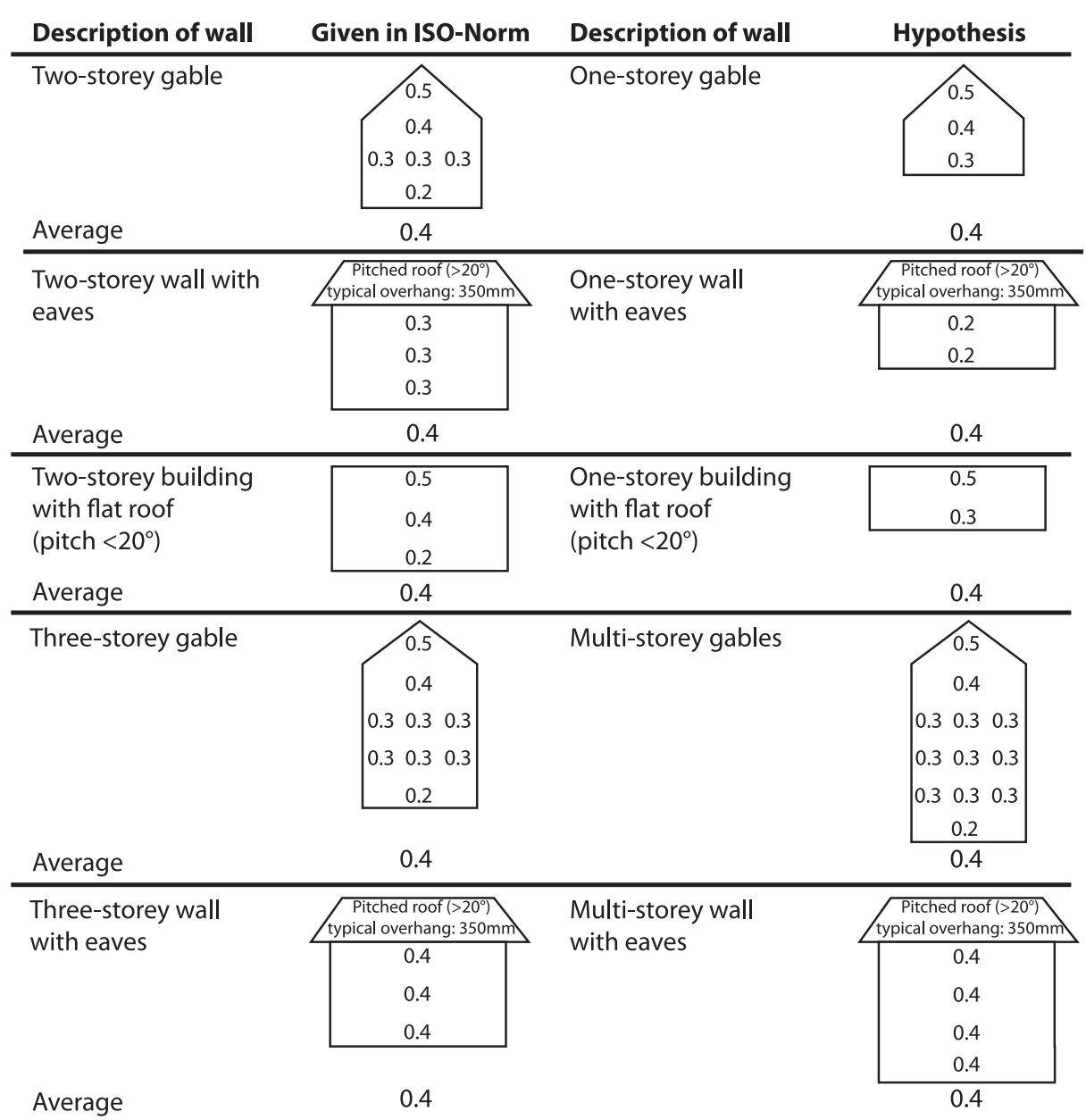

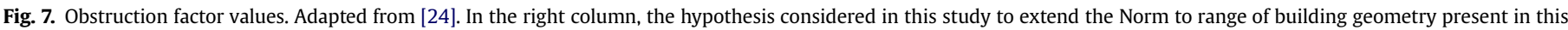
study.

proven to limit WDR on the upper part of the facade, it seems that it has very limited or no effect on the average WDR catch ratio for the whole facade, as modification on the wind field involved by eaves has the potential to increase WDR on another level (i.e. not right underneath the eave) of the facade $[37,42]$.

\section{Limits of applicability of the methodology}

Reasonable values for the wall spell index and catch ratio have been obtained (see section 5 ). However, several simplifications and assumptions have been made. The 3D-GIS database provided is very detailed but still does not perfectly fit with what is required by the ISO Norm 15927-3. On the other hand, we found situations in our case study where the ISO Norm does not give sufficient information on how to proceed in these specific cases. The assumptions

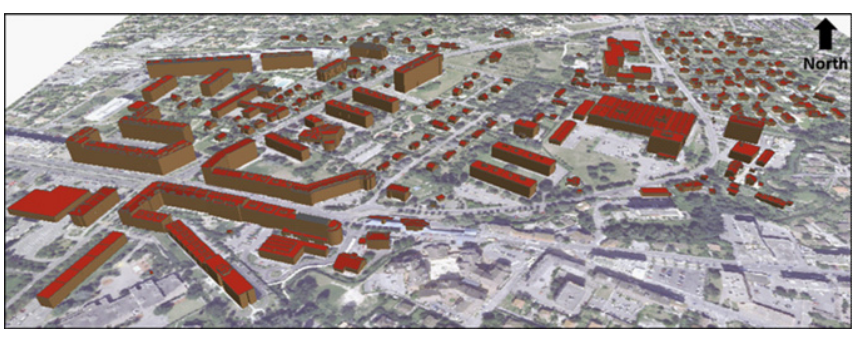

Fig. 8. 3D representation of the studied area. and simplifications that are made in this project are discussed in this section.

\subsection{Assumptions and simplifications during the GIS-data processing}

To estimate facade height above ground the different values of the pixels along wall lines are averaged to get one mean height for a certain facade. This affects mainly facades whose heights vary along the house. In the case of oblique roofs the shift of maximum facade height towards the average height of the facade considered may lead to underestimations.

However, because of wind-blocking effect, it has been shown by Blocken and Carmeliet [36] that high-rise buildings do not necessarily catch more rain than low rise buildings, which is nicely reproduced by the Norm (Fig. 10). This leads us to suppose that remaining uncertainties concerning facade height estimation has very limited influence on wall catch ratio estimates.

\subsection{Limits of applicability of the norm on city scale}

The ISO Norm describes the procedure to calculate the wall spell index for rather ordinary buildings. For unique or unorthodox types of buildings that are not reported in the ISO Norm, the wall factors are estimated by means of some interpolations (see Fig. 7). As mentioned in the previous section, the average wall factor varies between 0.2 and 0.4 . An error of 0.1 resulting from a change in 

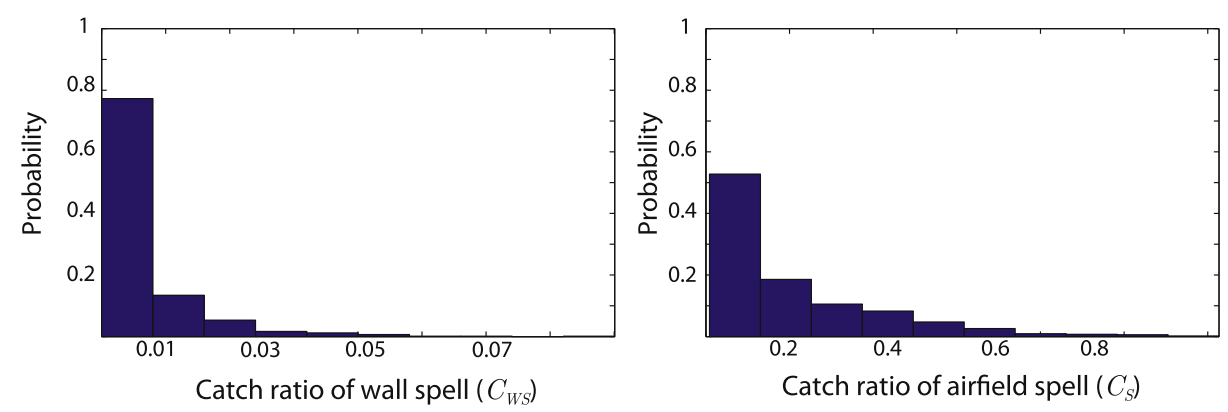

Fig. 9. Distribution of the wall catch ratio (left) and airfield catch ratio (right) for the area investigated.

category for the facade (see fig Fig. 7) that may occur due to our personal considerations can somehow affect the results. 50\% of the 1497 facades do not fit in the category proposed by the norm. It is a rather high proportion of actual buildings, and thus the Norm should be extended and upgraded to consider a wider range of building geometry. Such a task would require a specific study and is beyond the scope of this manuscript. Computational Fluid Dynamics (CFD) models have been shown to be able to overcome this issue [25-27].

Similarly, there are no specifications in the ISO Norm for the inner facades of a building, as discussed in section 3. In order to keep it simple, the inner facades are ignored in this project. About 60 of the 242 buildings considered possess this feature. It is not obvious what their exposure to the WDR is like as wind field in such complex building architecture is difficult to estimate. A proper analysis including 3-D GIS modelling and fluid mechanics simulations could be a useful a tool to approach an answer to this question.

In the context of the obstruction factor, the distance to the nearest obstacle with at least the same height as the facade concerned has to be determined. The Norm only proposes obstruction factors for obstacles located at more than $4 \mathrm{~m}$. But for obstacles closer than $4 \mathrm{~m}$ there is no obstruction factor given (see Table 2). In the case study considered, 172 facades ( $11 \%$ of all facades) have an obstacle closer than $1 \mathrm{~m}$ and for 217 facades (14\% of the total of facades) the nearest obstacle is between $1 \mathrm{~m}$ and $4 \mathrm{~m}$ away. Thus, extrapolation of the norm to estimate the obstruction factor for obstacles located closer than $4 \mathrm{~m}$ from the facade had to be made. In this project it is assumed that for an obstacle closer than $1 \mathrm{~m}$ the obstruction factor is zero (no water gets to the facade) and for obstacles between $1 \mathrm{~m}$ and $4 \mathrm{~m}$ an obstruction factor of 0.1 is supposed. It is difficult to evaluate the relevance of these assumptions, especially the one setting the obstruction factor to zero by an obstacle closer than $1 \mathrm{~m}$. By doing so, the wall spell index becomes zero. A tree standing in front of the facade may not cover the facade completely, even if it is very close. In such a case the wall spell factor may be underestimated. Again, we are listing here another shortcoming of the ISO Norm for its application to real case studies. The definition of the obstruction factor as it is given in the Norm seems to us the most limiting parameter of the Norm because it highly influences the wall catch ratio values (Fig. 10). This point was debated by Blocken et al. [27] and Blocken et al. [43] but more studies seem necessary to optimize obstruction factor definition in the Norm. Note that trees and buildings are treated the same way in terms of obstruction factor. However, trees are mostly porous, and provide some less obstruction to the wind flow. We treated trees and building the same way to keep consistency with the Norm directive. But there is another point that should receive supplementary details from the Norm.

In summary, the assumptions and simplifications made in this project are likely to generate certain errors. These errors affect the wall catch ratio as significant uncertainties listed stand on damping coefficients associated to building geometry and obstacles. It is not clear whether the final resulting error over or underestimates the wall catch ratio. Most the uncertainties are not due to insufficient precision in the 3-D GIS database, but have more to do with the fact that the ISO Norm has been detailed for a very limited number of building geometries.
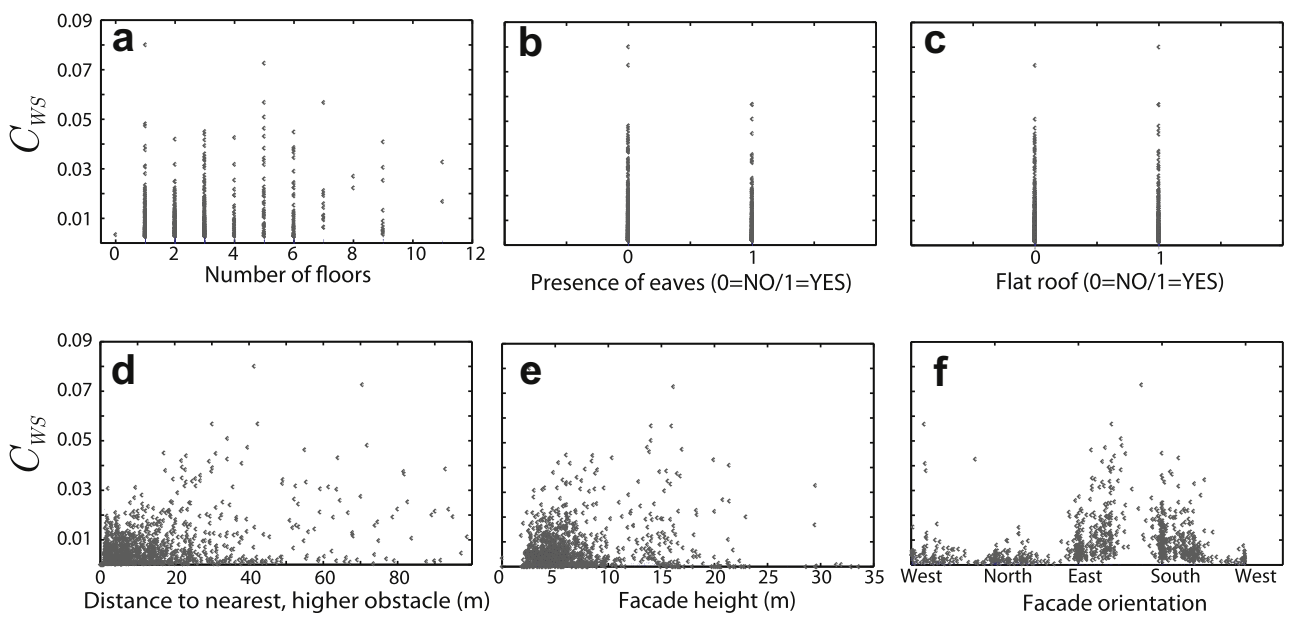

Fig. 10. Values of wall catch ratios as function of 6 different parameters. Each point represent one facade of the considered area. 


\section{Conclusion}

In the present project the wall catch ratio is calculated the way it is standardised in the ISO Norm 15927-3. The calculated catch ratio of water getting to the facade is lower than what has been usually found in other studies in the literature. This difference is partly explained by the fact that other current studies do not consider together the influence of surrounding buildings within a dense urban area. This conclusion is confirmed by the fact that the airfield catch ratios calculated i.e., the volume of water that gets to the facade when no obstacle is considered, match the ones found in the literature.

The orientation of facades has a considerable influence on WDR catch ratios. Facades oriented towards wind direction are systematically more affected by the incident rain. Moreover, the obstruction factor - i.e., the consideration of surroundings obstacles seems to play an important role in the determination of the wall catch ratio. But its definition as it has been given is limited and shows potential for strong improvement.

The results obtained seem to be realistic in general. It was possible to retrieve all necessary data from modern GIS techniques to compute the Norm in a large urbanized area. But for all wall indices some uncertainties exist. The ISO Norm 15927-3 can principally, apart from some meteorological constraints, be applied in very different regions with diverse densities of buildings. As it has only been designed for some ordinary types of facade shapes, the consistent application of the wall factor is, however, limited.

\section{References}

[1] Birkeland O. General report, rain penetration. paper 3-0, Helsinki. In: RILEM/CIB Symposium on moisture problems in buildings, vol. $3 ; 1965$. August 16-19.

[2] Gunn R. The terminal velocity of fall for water droplets in stagnant air. J Meteorol 1949;6:243-8.

[3] Toba T, Ohta T. Factors affecting rainfall interception determined by a forest simulator and numerical model. Hydrological Process 2008;22(14):2634-43. http://dx.doi.org/10.1002/hyp.6859.

[4] Dombrowski N, Foumeny EA, Ingham DB, Qi YD. Collection efficiencies of gauges at varying wind and pitch angles. Atmos Environ 1996;30(22):377788. http://dx.doi.org/10.1016/1352-2310(96)00116-1.

[5] Sharon D, Margalit A, Arazi A. The study of rainfall distributions in small watersheds in Israel: from early observations to model simulations. Iahs-Aish Publ 2000;261(261):13-28.

[6] Abuku M, Janssen H, Poesen J, Roels S. Impact, absorption and evaporation of raindrops on building facades. Build Environ 2009;44(1):113-24. http://dx. doi.org/10.1016/j.buildenv.2008.02.001.

[7] Hall C. Water movement in porous building materials-I. Unsaturated flow theory and its applications. Build Environ 1977;12(2):117-25. http://dx.doi. org/10.1016/0360-1323(77)90040-3.

[8] Hall C, Kalimeris AN. Water movement in porous building materials-V. Absorption and shedding of rain by building surfaces. Build Environ 1982; 17(4):257-62.

[9] Everett DH. The thermodynamics of frost damage to porous solids. Trans Faraday Soc 1961;57:1541-51.

[10] Franke L, Schumann I, van Hees R, van der Klugt L, Naldini S, Binda L, et al. Damage atlas, classification and analysis of damage patterns found in Brick Masonry. No. 8. In: European Commission research Report; 1998.

[11] Balen KV. Expert system for evaluation of deterioration of ancient brick masonry structures. Sci Total Environ 1996;189(0):247-54. http://dx.doi.org/ 10.1016/0048-9697(96)05215-1.

[12] Chew MYL. Defect analysis in wet areas of buildings. Construction Build Mater 2005;19(3):165-73. http://dx.doi.org/10.1016/j.conbuildmat.2004.07.005.

[13] Eldridge H. Common defects in buildings. Her majesty's stationery office; 1976.

[14] Burkhardt M, Zuleeg S, Vonbank R, Schmid P, Hean S, Lamani X, et al. Leaching of additives from construction materials to urban storm water runoff. Water Sci Technol 2011;63(9):1974-82. http://dx.doi.org/10.2166/wst.2011.128.

[15] Schoknecht U, Gruycheva J, Mathies H, Bergmann H, Burkhardt M. Leaching of biocides used in façade coatings under laboratory test conditions. Environ Sci Technol 2009;43(24):9321-8.

[16] Wittmer IK, Scheidegger R, Stamm C, Gujer W, Bader HP. Modelling biocide leaching from facades. Water Res 2011;45(11):3453-60. http://dx.doi.org/10. 1016/j.watres.2011.04.003.
[17] Zavadskas EK, Kaklauskas A, Raslanas S. Evaluation of investments into housing renovation. Int J Strategic Property Manag 2004;8(3):177-90. http:// dx.doi.org/10.1080/1648715X.2004.9637516.

[18] Blocken B, Carmeliet J. A review of wind-driven rain research in building science. J Wind Eng Ind Aerodynamics 2004;92(13):1079-130. http://dx.doi. org/10.1016/j.jweia.2004.06.003.

[19] Lundström-Gilliéron C, Schlaepfer R. Hare abundance as an indicator for urbanisation and intensification of agriculture in Western Europe. Ecol Mode 2003;168(3):283-301. http://dx.doi.org/10.1016/S0304-3800(03)00142-X.

[20] Blocken B, Carmeliet J. A simplified numerical model for rainwater runoff on building facades: possibilities and limitations. Build Environ 2012;53(1):5973. http://dx.doi.org/10.1016/j.buildenv.2012.01.010.

[21] Briggen PM, Blocken B, Schellen HL. Wind-driven rain on the facade of a monumental tower: numerical simulation, full-scale validation and sensitivity analysis. Build Environ 2009;44(8):1675-90. http://dx.doi.org/10.1016 j.buildenv.2008.11.003.

[22] Choi ECC. Determination of wind-driven-rain intensity on building faces. J Wind Eng Ind Aerodynamics 1994;51(1):55-69. http://dx.doi.org/10.1016/ 0167-6105(94)90077-9.

[23] Choi ECC. Simulation of wind-driven-rain around a building. J Wind Eng Ind Aerodynamics 1993;46-47(C):721-9.

[24] ISO/FDIS. Hygrothermal performance of buildings-climatic data-Part 3: calculation of a driving rain index for vertical surfaces from hourly wind and rain data; 2008. Final draft 15927-3, Geneva, Switzerland.

[25] Blocken B, Dezsö G, van Beeck J, Carmeliet J. Comparison of calculation models for wind-driven rain deposition on building facades. Atmos Environ 2010 44(14):1714-25. http://dx.doi.org/10.1016/j.atmosenv.2010.02.011.

[26] Blocken B, Carmeliet J. Overview of three state-of-the-art wind-driven rain assessment models and comparison based on model theory. Build Environ 2010;45(3):691-703.

[27] Blocken B, Abuku M, Nore K, Briggen PM, Schellen HL, Thue JV, et al. Intercomparison of wind-driven rain deposition models based on two case studies with full-scale measurements. J Wind Eng Ind Aerodynamics 2011;99(4): 448-59. http://dx.doi.org/10.1016/j.jweia.2010.11.004.

[28] Blocken B, Dezsö G, Beeck J, Carmeliet J. The mutual influence of two buildings on their wind-driven rain exposure and comments on the obstruction factor J Wind Eng Ind Aerodynamics 2009;97(5-6):180-96. http://dx.doi.org/10. 1016/j.jweia.2009.06.003.

[29] Pham TT, Musy M, Siret D, Teller J. Methodology for integrating and analyzing environmental and urban data in 3DGIS. 10th AGILE International Conference on Geographic Information Science. Aalborg Denmark, 8-11 May 2007, 12p., 2007.

[30] Baltsavias EP. Airborne laser scanning: basic relations and formulas. ISPRS J Photogrammetry Remote Sensing 1999;54:199-214. http://dx.doi.org/10. 1016/S0924-2716(99)00015-5.

[31] Jochem A, Hö fle B, Rutzinger M, Pfeifer N. Automatic roof plane detection and analysis in airborne LiDAR point clouds for solar potential assessment. Sensors 2009;9(7):5241-62. http://dx.doi.org/10.3390/s90705241.

[32] Lim C. Estimation of urban tree crown volume based on object-oriented approach and LiDAR data. Ph.D. thesis; International institute for Geoinformation Science and Earth Observation, Enschede, The Netherlands: 2007.

[33] Yoshida H, Omae M. An approach for analysis of urban morphology: methods to derive morphological properties of city blocks by using an urban landscape model and their interpretations. computers. Environ Urban Syst 2005;29(2): 223-47. http://dx.doi.org/10.1016/j.compenvurbsys.2004.05.008

[34] Tang W, Davidson C, Finger S, Vance K. Erosion of limestone building surfaces caused by wind-driven rain: 1. Field measurements. Atmos Environ 2004, 38(33):5589-99.

[35] Burrough PA, McDonell R. Principles of geographical information systems New York: Oxford University Press; 1998.

[36] Blocken B, Carmeliet J. The influence of the wind-blocking effect by a building on its wind-driven rain exposure. J Wind Eng Ind Aerodynamics 2006;94(2): 101-27. http://dx.doi.org/10.1016/j.jweia.2005.11.001

[37] Chen S, Wu X. Numerical study of wind-driven rain distribution on low-rise buildings with different roof styles. In: International Conference on Electric Technology and Civil Engineering, ICETCE 2011-Proceedings. 2011, p. 32823285.

[38] Tang W, Davidson CI. Erosion of limestone building surfaces caused by winddriven rain: 2. Numerical modeling. Atmos Environ 2004;38(33):5601-9. http://dx.doi.org/10.1016/j.atmosenv.2004.06.014.

[39] Högberg AB, Kragh MK, van Mook FJR. A comparison of driving rain measurements with different gauges. In: 5th Symposium on Building Physics in the Nordic Countries, Göteborg, Sweden. 1999, August 24-26.

[40] Karagiozis A, Hadjisophocleous G, Cao S. Wind-driven rain distributions on two buildings. J Wind Eng Ind Aerodynamics 1997;67-68:559-72.

[41] Burkhardt M, Zuleeg S, Vonbank R, Bester K, Carmeliet J, Boller M, et al. Leaching of biocides from facades under natural weather conditions. Environ Sci Technol 2012;46(10):5497-503. http://dx.doi.org/10.1021/es2040009.

[42] Abadie MO, Mendes N. Numerical assessment of turbulence effect on the evaluation of wind-driven rain specific catch ratio. Int Commun Heat Mass Transfer 2008;35(10):1253-61. http://dx.doi.org/10.1016/j.icheatmasstransfer.2008.08.013.

[43] Blocken B, Stathopoulos T, Carmeliet J. Wind environmental conditions in passages between two long narrow perpendicular buildings. J Aerospace Eng 2008;21(4):280-7. $\quad$ http://dx.doi.org/10.1061/(ASCE)0893-1321(2008)21: 4(280). 